Prepared for the U.S. Department of Energy

\title{
Determination of Adsorption Capacity and Kinetics of Amidoxime-Based Uranium Adsorbent Braided Material in Unfiltered Seawater Using a Flume Exposure System
}

\section{DOE-NE Milestone Report: M3FT-15PN0310055}

Gary A Gill, Li-Jung Kuo, Jonathan Strivens, Jiyeon Park, George Bonheyo, Robert Jeters, Nicholas Schlafer and Jordana Wood

Pacific Northwest National Laboratory, Marine Sciences Laboratory, Sequim, WA 98382

August 2015

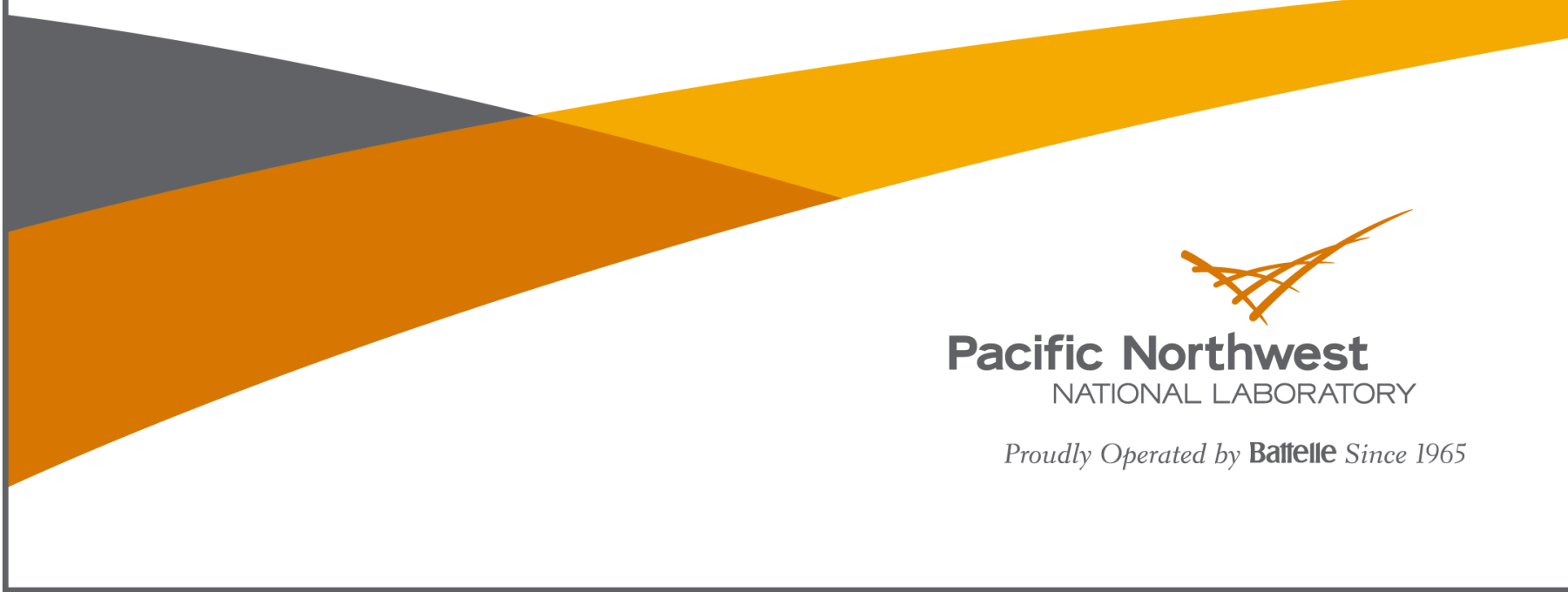




\title{
DISCLAIMER
}

This report was prepared as an account of work sponsored by an agency of the United States Government. Neither the United States Government nor any agency thereof, nor Battelle Memorial Institute, nor any of their employees, makes any warranty, express or implied, or assumes any legal liability or responsibility for the accuracy, completeness, or usefulness of any information, apparatus, product, or process disclosed, or represents that its use would not infringe privately owned rights. Reference herein to any specific commercial product, process, or service by trade name, trademark, manufacturer, or otherwise does not necessarily constitute or imply its endorsement, recommendation, or favoring by the United States Government or any agency thereof, or Battelle Memorial Institute. The views and opinions of authors expressed herein do not necessarily state or reflect those of the United States Government or any agency thereof.

\author{
PACIFIC NORTHWEST NATIONAL LABORATORY \\ operated by \\ BATTELLE \\ for the \\ UNITED STATES DEPARTMENT OF ENERGY \\ under Contract DE-AC05-76RL01830 \\ Printed in the United States of America \\ Available to DOE and DOE contractors from the \\ Office of Scientific and Technical Information, \\ P.O. Box 62, Oak Ridge, TN 37831-0062; \\ ph: (865) 576-8401 \\ fax: $(865) 576-5728$ \\ email: reports@adonis.osti.gov \\ Available to the public from the National Technical Information Service \\ 5301 Shawnee Rd., Alexandria, VA 22312 \\ ph: (800) 553-NTIS (6847) \\ email: $\underline{\operatorname{orders}(\boldsymbol{a} \text { ntis.gov }}<\mathrm{http}: / /$ www.ntis.gov/about/form.aspx $>$ \\ Online ordering: http://www.ntis.gov
}




\section{Determination of Adsorption Capacity and Kinetics of Amidoxime-Based Uranium Adsorbent Braided Material in Unfiltered Seawater Using a Flume Exposure System}

Prepared for: U. S. Department of Energy, Office of Nuclear Energy, Fuel Cycle Research and Development Program, Fuel Resources Program

Prepared by: Gary A Gill, Li-Jung Kuo, Jonathan Strivens, Jiyeon Park, George Bonheyo, Robert Jeters, Nicholas Schlafer and Jordana Wood

Pacific Northwest National Laboratory

Marine Sciences Laboratory, Sequim, WA 98382

Milestone Number: M3FT-15PN0310055

Milestone Due Date: 8-1-2015

Milestone Level: M3

FCRD Document Number: FCRD-MRWFD-2015-000477

Work Package Number: FT-15PN031005

U. S. DOE-NE Program Manager: Dr. Stephen Kung

PNNL Information Release Number: PNNL-24543

Prepared for: the U.S. Department of Energy under Contract DE-AC05-76RL01830, Pacific

Northwest National Laboratory, Richland, Washington 99352 


\section{Executive Summary}

PNNL has developed a recirculating flume system for exposing braided adsorbent material to natural seawater under realistic temperature and flow-rate exposure conditions. The flumes are constructed of transparent acrylic material they allow external light to pass into the flumes and permit photosynthetic growth of naturally present marine organisms (biofouling). Because the system consists of two flumes, replicate experiments can be conducted in which one of the flumes can be manipulated relative to the other. For example, one flume can be darkened to eliminate light exposure by placing a black tarp over the flume such that dark/light experiments can be conducted. Alternatively, two different braided adsorbents can be exposed simultaneously with no potential cross contamination issues.

This report describes the first use of the PNNL flume system to study the impact of biofouling on adsorbent capacity. Experiments were conducted with the ORNL AI8 braided adsorbent material in light exposed and darkened flumes for a 42 day exposure experiment. The major objective of this effort is to develop a system for the exposure of braided adsorbent material to unfiltered seawater and to demonstrate the system by evaluating the performance of adsorption material when it is exposed to natural marine biofouling as it would be when the technology is used in the marine environment. Exposures of amidoxime-based polymeric braid adsorbents prepared by Oak Ridge Natural Laboratory (ORNL) were exposed to ambient seawater at $20^{\circ} \mathrm{C}$ in a flume system. Adsorption kinetics and adsorption capacity were assessed using time series determinations of uranium adsorption and one-site ligand saturation modeling.

Biofouling in sunlight surface seawater has the potential to significantly add substantial biogenic mass to adsorption material when it is exposed for periods greater than 21 days. The observed biomass increase in the light flume was approximately $80 \%$ of the adsorbent mass after 42 days. The amount of biomass increase retained by the adsorbent in the dark flume was only a quarter of that observed in the light exposed flume. Biofouling in sunlit surface seawater has the potential to reduce uranium adsorption capacity by $\sim 30 \%$ after 42 days of exposure. Minimal or no adsorption loss due to biofouling occurred in the dark flume exposure.

Attempts to assess time series measurements of uranium adsorption capacity using "snips" off a master braid, as in previous filtered flume studies, are fraught with problems due to the inability to easily determine the mass of the adsorbent material when the biofouling is present. At this point, the only clear way to address this issue is to expose pre-weighed "mini-braids" that are created from the master braid. The ability to determine the adsorption of biogenically important trace elements (e.g. Fe, $\mathrm{Mn}, \mathrm{Zn}, \mathrm{Cu}$, and $\mathrm{Sr}$ ) on biofouled adsorbents is also problematic. This difficulty arises because many of the elements of interest are also major components in biogenic material. When a biofouled adsorbent is digested for analysis, the elemental concentrations that are observed are a result of the element retained on the adsorbent and the contribution from the biogenic material attached to the adsorbent. For elements like uranium, this is not an issue because uranium is not a required element for biological growth and thus it is in extremely low concentrations in biogenic material. 



\section{Acronyms and Abbreviations}

$\begin{array}{ll}\text { DOM } & \text { dissolved organic matter } \\ \text { MSL } & \text { Marine Sciences Laboratory } \\ \text { NIST } & \text { National Institute of Standards and Technology } \\ \text { ORNL } & \text { Oak Ridge National Laboratory } \\ \text { PNNL } & \text { Pacific Northwest National Laboratory } \\ \text { TOC } & \text { Total Organic Carbon }\end{array}$





\section{Contents}

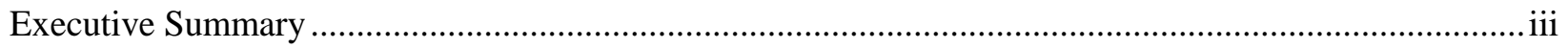

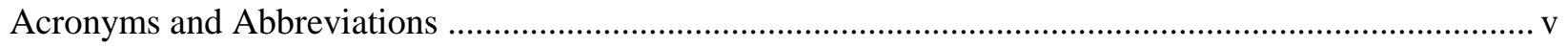

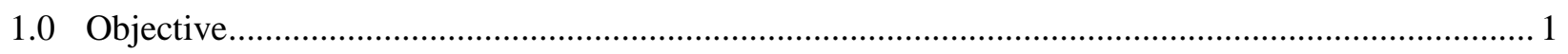

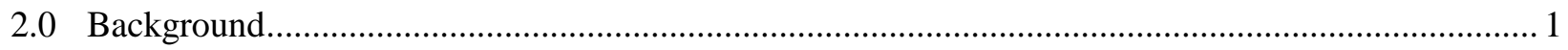

$3.0 \quad$ Experimental Approach .................................................................................................... 1

3.1 PNNL Ambient Seawater Flume Exposure System......................................................... 1

3.1.1 Ambient Seawater Delivery ............................................................................. 1

3.1.2 Recirculating Flume Exposure System …............................................................... 3

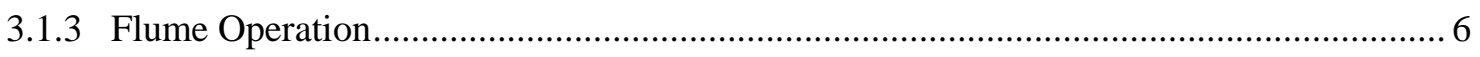

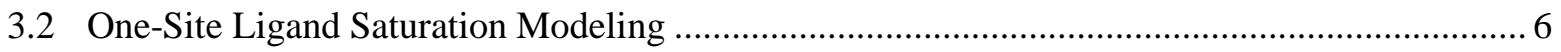

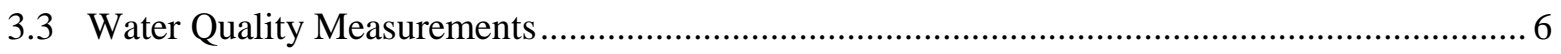

3.3.1 Determination of Uranium and Trace Elements on Adsorbent Materials ....................... 6

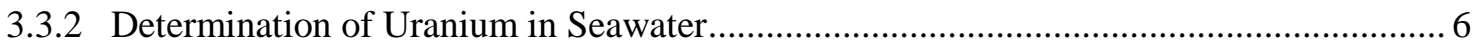

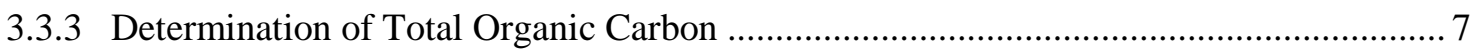

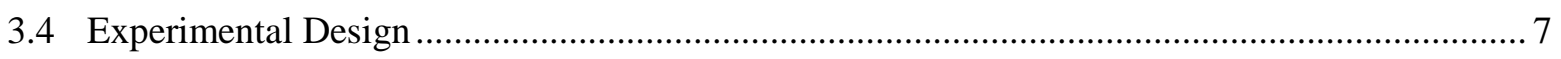

3.4.1 Mass Accumulation of Biofouling with Time of Exposure ......................................... 9

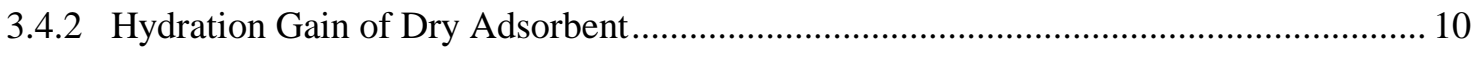

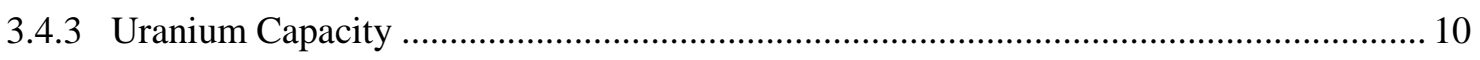

3.4.4 Biofouling Mass Accumulation via Total Organic Carbon Measurements .................... 10

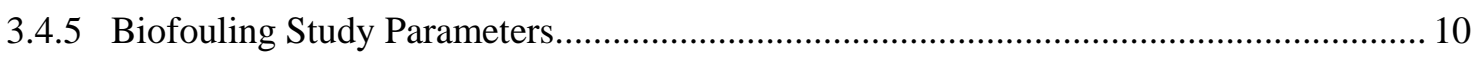

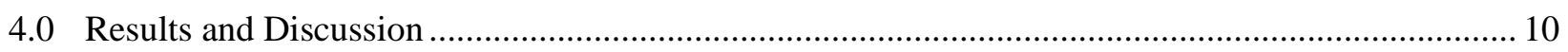

4.1 Biofouling of Adsorbent Material in Light and Dark Flume Exposures with $150 \mu \mathrm{m}$

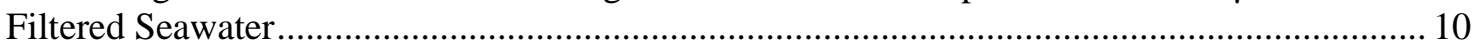

4.2 Comparison of Uranium Adsorption Capacity in Dark and Light Flumes with $150 \mu \mathrm{m}$ Filtered Seawater Exposure ........................................................................................ 13

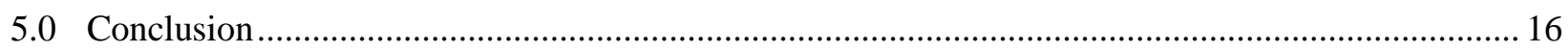

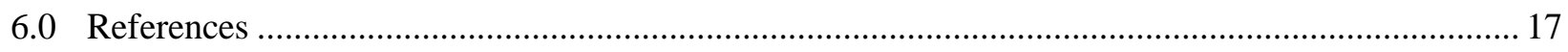




\section{Figures}

Figure 1. Big Bubba Filter System for Gross Filtration of Large Debris from Ambient Seawater. The unfiltered seawater was filtered through a $150 \mu \mathrm{m}$ filter and delivered to a head tank for temperature control.

Figure 2. $180 \mathrm{~L}$ head tank for temperature control in seawater exposure experiments. The titanium immersion heater and controller system are shown in the upper right side of the picture. The pump which draws out the temperature controlled water and delivers it to the manifold on the seawater table is shown on the lower left side of the picture.

Figure 3. Translucent Flumes for Unfiltered Seawater Exposure Studies with Braided Adsorbent Material. The pumps used to recirculate water in the flume and control the linear velocity of the flow are shown in the upper left side of the picture. The manifold that that distributes fresh seawater into the flumes sits between the two flumes.

Figure 4. Conceptual side view of the recirculating flume showing fresh seawater introduced from the temperature controlled head tank, the overflow tube to control water depth, and the pump recirculation system.

Figure 5. Adsorbent braid attached to a short length of 1/4-inch polyethylene tubing. The tubing is then inserted into a (gray PVC) block attached to the bottom of the flume (see Figure 3).....

Figure 6. Light and Dark Flumes used for the Biofouling Exposure Study with $150 \mu \mathrm{m}$ Filtered Seawater

Figure 7. Overall Sampling Design for Determination of the Impact of Biofouling on Adsorption Capacity. The sampling periods are 0, 7, 14, 21, 28 and 42 days. The individual experiments are given by the yellow boxes in each row. The darkened boxes represent where replicate samples were collected. $\mathrm{MB}=$ mini braid, and $\mathrm{B}=$ main braid. The \# indicates the specific sample number.

Figure 8. Layout of Main Braid and Mini Braids in the Dark and Light Flumes for the Unfiltered Seawater Biofouling Exposure Study. The main braid was positioned near the seawater recirculation inlet. The dark flume had 5 mini braids and the light flume had 14 mini braids

Figure 9. (A) Mini Braid Held Together with Fishing Line Prior to Conditioning; (B)

Conditioned Mini Braids attached to tubing in the Flume (C) Braided Adsorbent Before

Conditioning with $\mathrm{KOH}$; (D) $\mathrm{KOH}$ Conditioned Braid Secured Inside the Flume.

Figure 10. Biofouling mass accumulation as a function of time in light exposed and dark flumes for a 42 day exposue experiment with $150 \mu \mathrm{m}$ filtered seawater.

Figure 11. Light Exposed and Dark Bioflouling Experiment Flumes at the Start of the Experiment (Left Panel) and After 42 Days of Exposure to $150 \mu \mathrm{m}$ Filtered Seawater. The Level of Biofouling in the Light Exposed Tank is Visually Apparent.

Figure 12. 42 Day Biofouling Experiment in the PNNL Flume with the ORNL AI8 Adsorbent. The green circles represent the time series results obtained from the mini braid samples in the light exposed flume. The black squares represent replicate measurements of the 42 day exposure time in the dark flume. The red diamonds represent a subsample of the main braid that was exposed in a PNNL flow-through column for 42 days in $0.30 \mu \mathrm{m}$ filtered water in the dark. This samples serves as a control. The blue triangles are from a previous time series experiment conducted with the ORNL AI8 adsorbent in flow-through columns exposures in the dark at $20^{\circ} \mathrm{C}$. This data serves as a reference only. Lines drawn through the data points are from one-site ligand saturation modelling.

Figure 13. Comparison of 42 Day Exposure of the ORNL AI8 Adsorbent Capacity in Light Exposed and Darkened Flumes That Received $150 \mu \mathrm{m}$ Filtered Seawater. The Control Sample Represents Snips of the AI8 Braid Exposed to $0.30 \mu \mathrm{m}$ Filtered Seawater in a PNNL 
Flow-through Column Exposure. The Reference Sample Represents a Previous Time Series Experiment Conducted with the ORNL AI8 Adsorbent in Flow-through Columns Exposures in the Dark at $20{ }^{\circ} \mathrm{C}$.

Figure 14. Global Chlorophyll a concentration (figure from NASA;

http://earthobservatory.nasa.gov/GlobalMaps/view.php?d1=MY1DMM_CHLORA) 


\subsection{Objective}

The Pacific Northwest National Laboratory (PNNL) has a level 3 milestone (M3FT-15PN0310055) to "Complete testing of a braided material with unfiltered seawater and issue a report on effect on adsorption capacity and kinetics". There is a companion level 3 Milestone Report (M3FT-15PN0310057) entitled "Impact of Marine Biofouling on the Adsorption Capacity and Kinetics of Amidoxime-Based Uranium Adsorbent Materials" that is being conducted simultaneously with this effort. The major objectives of these efforts is to evaluate the performance of adsorption material when it is exposed to natural marine biofouling as it would be when the technology is used in the marine environment. The main performance criteria are adsorption capacity and kinetics. The effect of biofouling will be evaluated based on comparison with experiments conducted in the absence of biofouling. This current report will focus on adsorption capacity and kinetics and the companion report will delve deeper into understanding the nature and characteristics of the biofouling as it relates to adsorbent performance in real seawater.

\subsection{Background}

The Fuel Resources Program at the U.S. Department of Energy's Office of Nuclear Energy is developing adsorbent technology to extract uranium from seawater. This technology is being developed to provide a sustainable and economically viable supply of uranium fuel for nuclear reactors (DOE, 2010). A major effort in the development of this technology at PNNL is to test the performance of the uranium adsorption materials being developed in natural seawater with realistic marine conditions. Marine testing consists of exposing amidoxime-based fibers to natural seawater in flow-through column tests and braided adsorbents in recirculating flumes. The vast majority of the initial marine testing at PNNL to date has been conducted with filtered $(<0.45 \mu \mathrm{m})$ ambient seawater, which excludes photosynthetic algae and larval organisms from adhering to and growing on the fibers, a process generally referred to as "biofouling". The deployment of uranium adsorbent technology in the ocean will involve exposure to raw seawater and all the live and dead biogenic materials it contains. Hence, it is important to understand how adsorption capacities and adsorption kinetics will be affected by exposure to natural seawater, compared to filtered seawater.

\subsection{Experimental Approach}

Exposure of amidoxime-based polymeric braid adsorbents prepared by Oak Ridge Natural Laboratory (ORNL) were exposed to ambient seawater at $20^{\circ} \mathrm{C}$ in a flume system. Adsorption kinetics and adsorption capacity were assessed using time series determinations of uranium adsorption and one-site ligand saturation modeling.

\subsection{PNNL Ambient Seawater Flume Exposure System}

\subsubsection{Ambient Seawater Delivery}

Marine testing was conducted using ambient seawater from Sequim Bay, WA. PNNL's Marine Sciences Laboratory (MSL) has a seawater delivery system that can provide ambient seawater into a "wet laboratory" for scientific investigations. Ambient seawater is drawn by pump from a depth of $\sim 10 \mathrm{~m}$ 
from Sequim Bay through a plastic pipe. The unfiltered seawater is delivered to the wet laboratory for use through a PVC piping system. Gross filtration of the ambient seawater is conducted to remove large debris using a Big Bubba ${ }^{\circledR}$ non-metallic filter housing and a $150 \mu \mathrm{m}$ Big Bubba $^{\circledR}$ pleated filtration cartridge (Figure 1). Filtration at $150 \mu \mathrm{m}$ should not remove most phytoplankton species which contribute to biofouling, but will remove larger marine plankton. Temperature control for experimental purposes is achieved by feeding the $150 \mu \mathrm{m}$ filtered seawater into a $180 \mathrm{~L}$ head tank that has a $10,000 \mathrm{~W}$ titanium immersion heater (Figure 2). The temperature in the head tank can be maintained between ambient ${ }^{1}$ and roughly $40{ }^{\circ} \mathrm{C}$, with a variability of approximately $\pm 1.5^{\circ} \mathrm{C}$ around the set point. Temperature controlled water is drawn out of the head tank using a pump and delivered to a multi-port manifold on the wetlab table for experimental distribution.

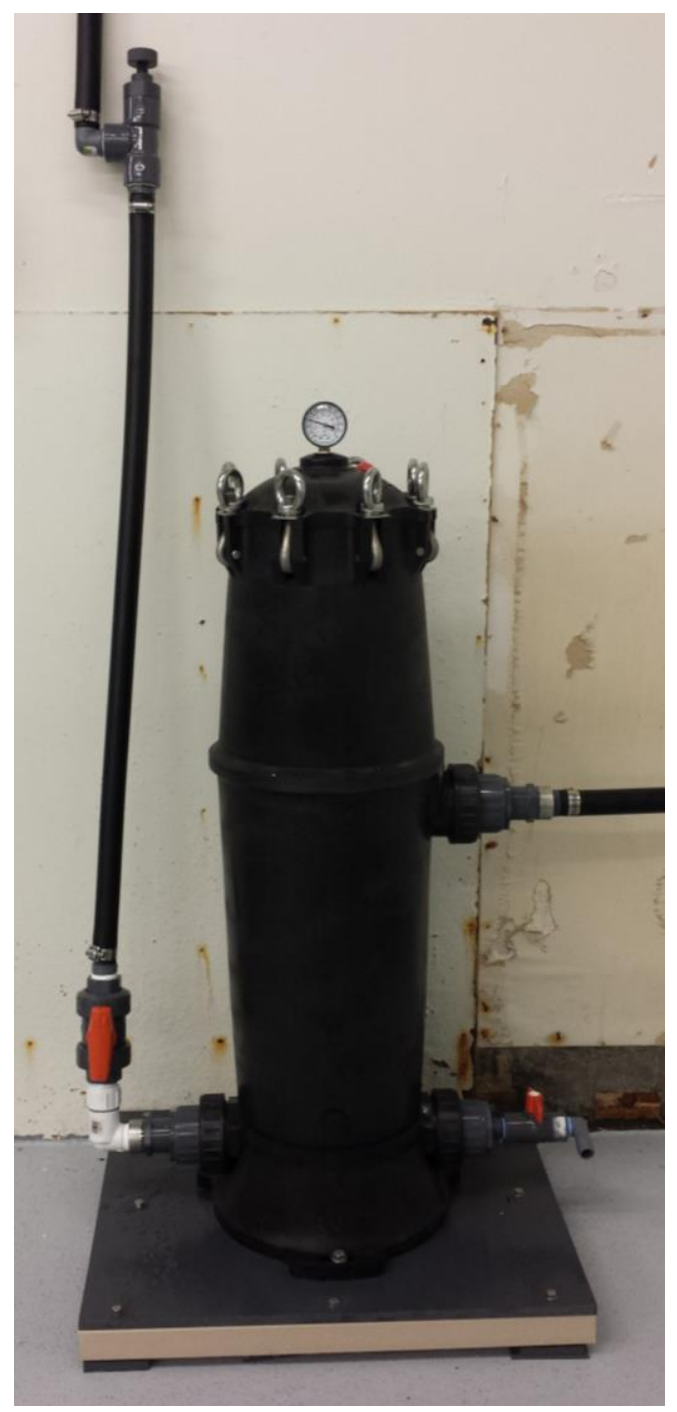

Figure 1. Big Bubba Filter System for Gross Filtration of Large Debris from Ambient Seawater. The unfiltered seawater was filtered through a $150 \mu \mathrm{m}$ filter and delivered to a head tank for temperature control.

\footnotetext{
${ }^{1}$ Ambient seawater in Sequim Bay typically varies from a low of around $7{ }^{\circ} \mathrm{C}$ in winter to a high of around $13{ }^{\circ} \mathrm{C}$ in summer.
} 


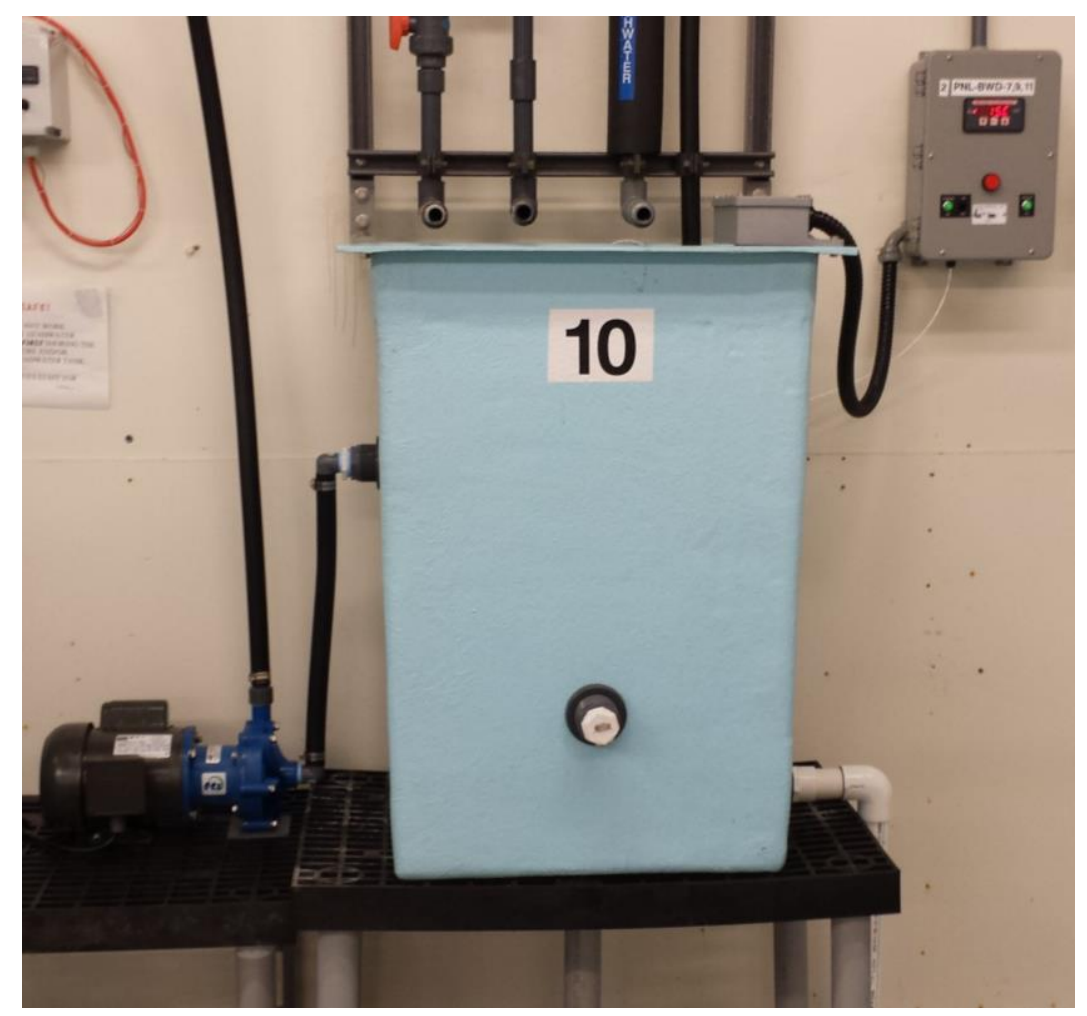

Figure 2. $180 \mathrm{~L}$ head tank for temperature control in seawater exposure experiments. The titanium immersion heater and controller system are shown in the upper right side of the picture. The pump which draws out the temperature controlled water and delivers it to the manifold on the seawater table is shown on the lower left side of the picture.

\subsubsection{Recirculating Flume Exposure System}

PNNL has developed recirculating flumes for conducting exposure tests with braided adsorbent material under controlled temperature and flow-rate conditions. For exposures with unfiltered seawater, the flumes are constructed of an acrylic material to allow ambient light to pass to the seawater in the flume. Allowing light penetration will permit growth of photosynthetic organisms (biofouling) as would occur in the natural seawater environment. Two translucent flumes were built for this study (Figure 3). The translucent flumes have physical dimensions identical to the narrower opaque flume developed previously for filtered seawater exposure studies (Table 1).

Fresh seawater is constantly fed into the flume using the manifold and tubing delivery system (see Figures 3 and 4 ) at a rate up to $8 \mathrm{~L} /$ minute. The rate of fresh seawater delivery is controlled using a needle valve on one or more ports in the manifold. The rate of fresh seawater delivery depends primarily on the total mass of adsorbent material undergoing seawater exposure. Fresh seawater needs to be fed into the flume at a rate greater than it is being removed from solution by the adsorbent. Based on previous experience, a flow-rate $>1.5 \mathrm{~L} /$ minute will result in minimal drops in the uranium concentration in the flume when the total mass of adsorbent being exposed is $<5 \mathrm{~g}$.

Controlled water flow within the flume is accomplished by recirculating water using a centrifugal water pump (Finish Thompson). The pump head is all non-metallic to minimize contamination concerns. Precise control of flow-rate/linear velocity was achieved by putting a flow restriction (globe valve) at the outlet of the pump (Figure 4). The flow-rate in the recirculating water was continuously monitored by 
placing a flow meter (Omega) in the line between the flume outlet and pump inlet. The target for these studies is a flow-rate that results in a linear velocity of $>2 \mathrm{~cm} / \mathrm{sec}$. This linear velocity was chosen to be consistent with the linear velocity used in flow-through column studies. The linear velocity in the tank was determined using the cross-sectional area of the tank and the recirculation flow-rate. For example, a linear velocity of $2 \mathrm{~cm} / \mathrm{s}$ was achieved in the 6 foot flume with a $20.3 \mathrm{~cm}$ water height (cross-sectional area of $\left.300 \mathrm{~cm}^{2}\right)$ using the lower capacity pump and setting the flow-rate to $9 \mathrm{gpm}(34 \mathrm{~L} / \mathrm{min})$. There is a slight increase in linear velocity ( 9\%) due to the fresh seawater inflow of $2-4 \mathrm{~L} / \mathrm{min}$, but it is small relative to the recirculation flow of $34 \mathrm{~L} / \mathrm{min}$.

The height of water in the flume is controlled by the height of the standpipe, which can be varied between approximately 6 and 10 inches. The nominal height is 9 inches. Water within the system rises until it reaches the height of the standpipe and then spills out of the flume through the standpipe.

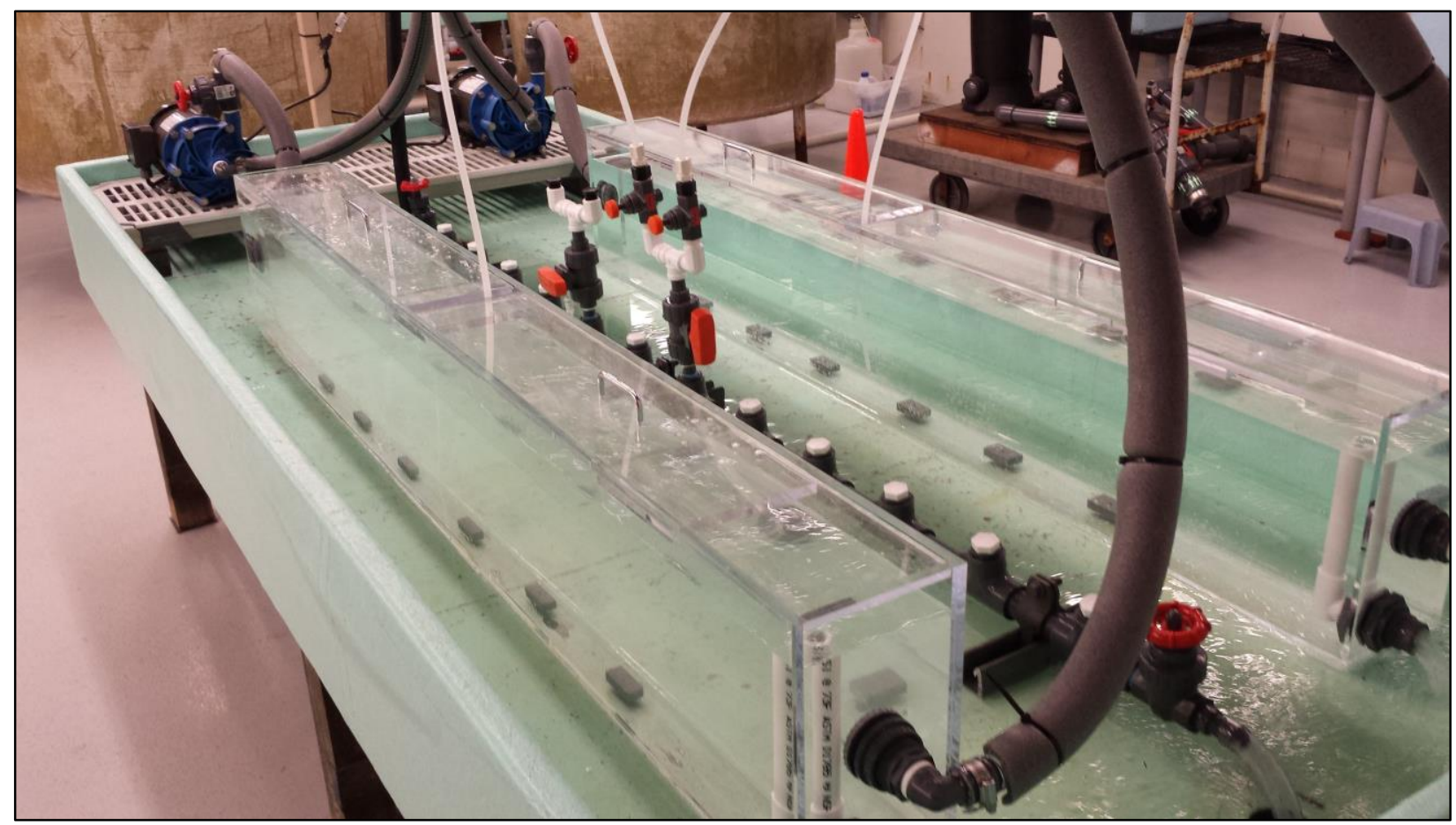

Figure 3. Translucent Flumes for Unfiltered Seawater Exposure Studies with Braided Adsorbent Material. The pumps used to recirculate water in the flume and control the linear velocity of the flow are shown in the upper left side of the picture. The manifold that that distributes fresh seawater into the flumes sits between the two flumes.

Table 1. PNNL Translucent Flume Dimensions

\begin{tabular}{|c|c|c|c|c|}
\hline $\begin{array}{c}\text { Internal } \\
\text { Length } \\
(\mathbf{c m})\end{array}$ & $\begin{array}{c}\text { Internal } \\
\text { Width } \\
(\mathbf{c m})\end{array}$ & $\begin{array}{c}\text { Target } \\
\text { Internal } \\
\text { Depth } \\
(\mathbf{c m})\end{array}$ & $\begin{array}{c}\text { Cross } \\
\text { Sectional } \\
\text { Area } \\
\left(\mathbf{c m}^{2}\right)\end{array}$ & $\begin{array}{c}\text { Volume } \\
(\text { L) }\end{array}$ \\
\hline 183 & 15.2 & 20.3 & 304 & 56 \\
\hline
\end{tabular}




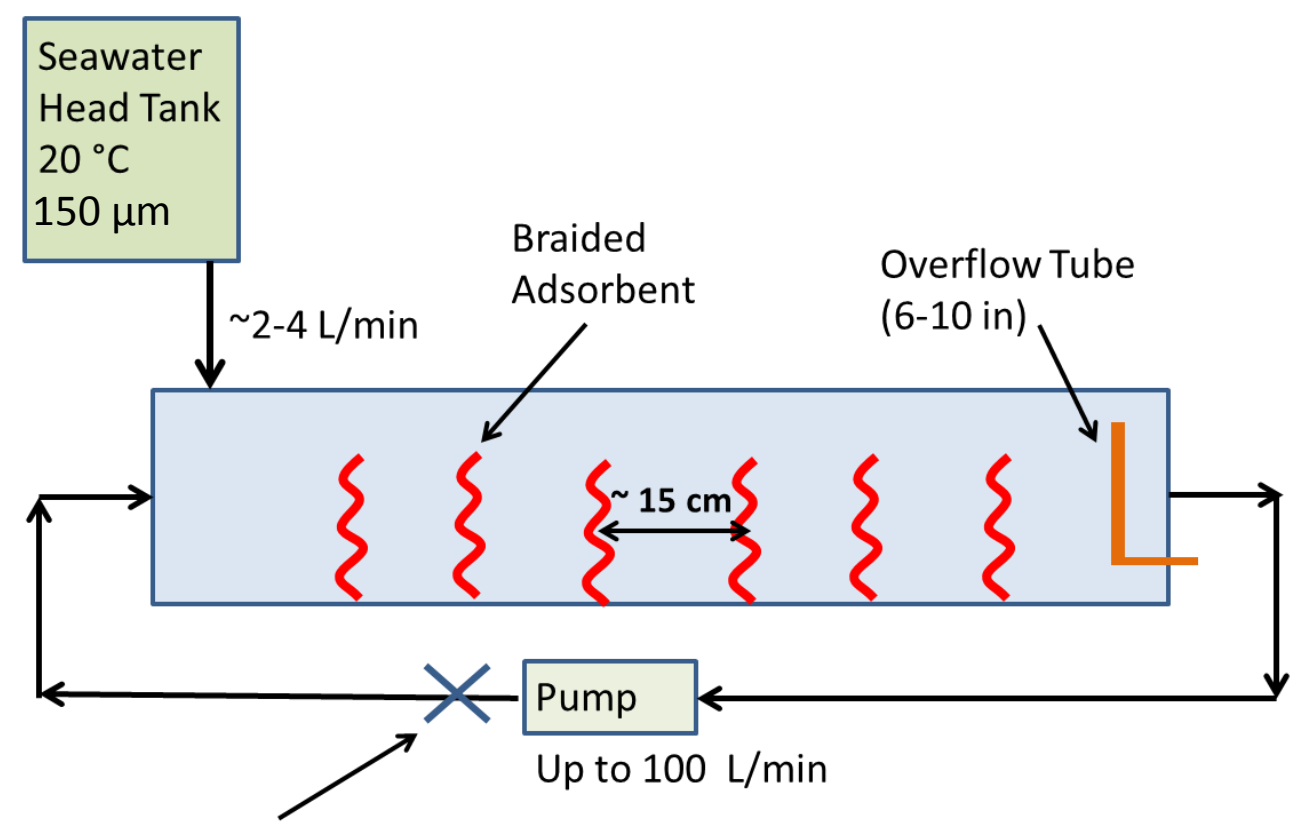

Flow Restriction

Figure 4. Conceptual side view of the recirculating flume showing fresh seawater introduced from the temperature controlled head tank, the overflow tube to control water depth, and the pump recirculation system.

The rate at which water is fed into the system and the internal volume of the flume controls the residence time of new water in the system. For the above example with the $6 \mathrm{ft}$ flume, the water residence time is 18.9 minutes. The time to recirculate water is much faster. At a recirculation flow rate of $34 \mathrm{~L} / \mathrm{min}$, the water in the flume is recirculated once every 1.7 minutes. Hence, the water in the flume is well mixed.

Braided adsorbents are placed into the flumes by attaching them to a short length of $1 / 4$ inch polyethylene tubing with cable ties and inserting one end of the tubing into a small block mounted on the bottom of the flume into which a $1 / 4$ inch hole has been drilled. Multiple braids can be mounted in a single flume of desired (Figure 5).

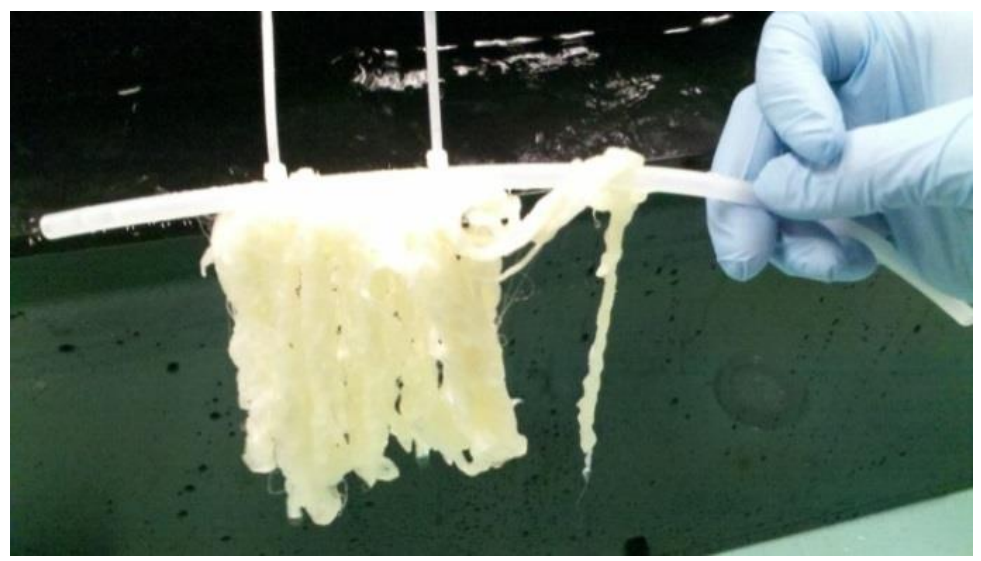

Figure 5. Adsorbent braid attached to a short length of 1/4-inch polyethylene tubing. The tubing is then inserted into a (gray PVC) block attached to the bottom of the flume (see Figure 3). 


\subsubsection{Flume Operation}

The dimensions of the translucent flume used in this study were given in Table 1 . The water depth in the flume was held at $22.9 \mathrm{~cm}$ (9 inches), making the total volume in the flume $64 \mathrm{~L}$. The flow rate of fresh $150 \mu \mathrm{m}$ filtered seawater was introduced at $3 \mathrm{~L} / \mathrm{min}$. The seawater recirculation pump was adjusted to $40 \mathrm{~L} / \mathrm{min}(10.5 \mathrm{GPM})$. The combination of the introduction of fresh seawater and recirculated seawater produced a linear velocity of $2.0 \mathrm{~cm} / \mathrm{sec}$. Seawater temperature was controlled at $20 \pm 1.5^{\circ} \mathrm{C}$. The temperature of the seawater in the flume was monitored using an Omega model HH804U handheld meter equipped with a long lead and non-metallic temperature probe. The water residence time with respect to fresh seawater input under the flow conditions described above was 21 minutes. The water residence time with respect to re-circulation under the conditions described above was 1.6 minutes.

\subsection{One-Site Ligand Saturation Modeling}

The binding of the uranyl ion to the amidoxime-based polymeric adsorbent was evaluated using a one-site ligand saturation model, which was parameterized using the software graphics program SigmaPlot $\odot$. The best-fit line representing the time series adsorption of uranium is given by:

$$
u=\frac{\beta_{\max } t}{K_{d}+t}
$$

Where $u$ is uranium capacity (g U/kg adsorbent), $t$ is exposure time (days), $\beta_{\max }$ is the adsorption capacity at saturation (g U/kg adsorbent), and $K_{d}$ is the half-saturation time (days).

\subsection{Water Quality Measurements}

Salinity and $\mathrm{pH}$ measurements were conducted daily. Salinity was determined using a handheld YSI salinometer. The $\mathrm{pH}$ was measured with a standard $\mathrm{pH}$ meter and probe that was calibrated weekly using NIST-traceable buffers.

\subsubsection{Determination of Uranium and Trace Elements on Adsorbent Materials}

Adsorbent materials exposed to seawater were washed with deionized water to remove salts, and the monitoring the process with a conductivity meter. Samples were then dried at $80^{\circ} \mathrm{C}$ to a constant weight using a heated block (ModBlock ${ }^{\mathrm{TM}}$, CPI International). The dried fibers (50 to $100 \mathrm{mg}$ ) were weighed and then digested with $10 \mathrm{~mL}$ of a high-purity (Optima Grade, Fisher Scientific) 50\% aqua regia acid mixture (3:1; hydrochloric acid: nitric acid) for 3 hours at $85^{\circ} \mathrm{C}$ on a hot block. Analysis of uranium and other trace elements was conducted using either a Perkin-Elmer 4300 inductively coupled plasma optical emission spectrometer or a Thermo Scientific ICap ${ }^{\mathrm{TM}} \mathrm{Q}$ inductively coupled plasma mass spectrometer. Quantification with both instruments is based on standard calibration curves.

\subsubsection{Determination of Uranium in Seawater}

Determination of uranium in natural seawater samples was conducted using inductively coupled plasma mass spectrometry and the method of standard addition calibrations. Addition calibration is a variant of the standard additions method and is often used when all samples have a similar matrix. 
Instrumental calibration curves were prepared in Sequim Bay seawater that was diluted 20-fold with high purity deionized water and then spiked at four different concentration levels: $0.1,0.2,0.3$, and $0.4 \mu \mathrm{g} / \mathrm{L}$, along with a $2 \%$ nitric acid blank in the diluted seawater. The seawater samples were then analyzed at 20-fold dilution with high purity deionized water and then quantified using the matrix matched additions calibration curve. The standard reference material CASS-5 (Nearshore Seawater Reference Material for Trace Metals) available from the National Research Council Canada, which is certified for uranium (3.18 $\pm 0.10 \mu \mathrm{g} / \mathrm{L}$ ), was also analyzed at a 20 -fold dilution every 10 samples to verify the analytical results. The uranium recovery for the analysis of CASS-5 ranged from $93 \%$ to $99 \%(n=9)$. Duplicate analyses and matrix spikes were conducted with each batch of samples. The relative percent difference for duplicates ranged from $1 \%$ to $5 \%$, and the recovery of matrix spikes ranged from $93 \%$ to $109 \%(\mathrm{n}=11)$.

\subsubsection{Determination of Total Organic Carbon}

Measurements of Total Organic Carbon (TOC) were conducted using a high temperature catalytic combustion instrument (Shimadzu TOC analyzer).

\subsection{Experimental Design}

Two flumes were set up for exposure of braided adsorbent with unfiltered seawater, one with light exposure and a darkened flume (Figure 6). A cover of black plastic was used to create the darkened flume. The darkened flume is intended to represent the conditions in deep water where minimal light penetrates to depth. A series of 6,75 watt, daylight spectrum compact fluorescent lights was used to illuminate the light tank on a 12 hour on, 12 hour off photoperiod. The intensity of light at the surface of the water in the flume was around $50 \mu$ Einstein's $\mathrm{m}^{-2} \mathrm{sec}^{-1}$, a small fraction of the light intensity of a bright summer day at noon $\left(2,000 \mu \mathrm{mol}\right.$ of photons $\left.\mathrm{m}^{-2} \mathrm{sec}^{-1}\right)$.

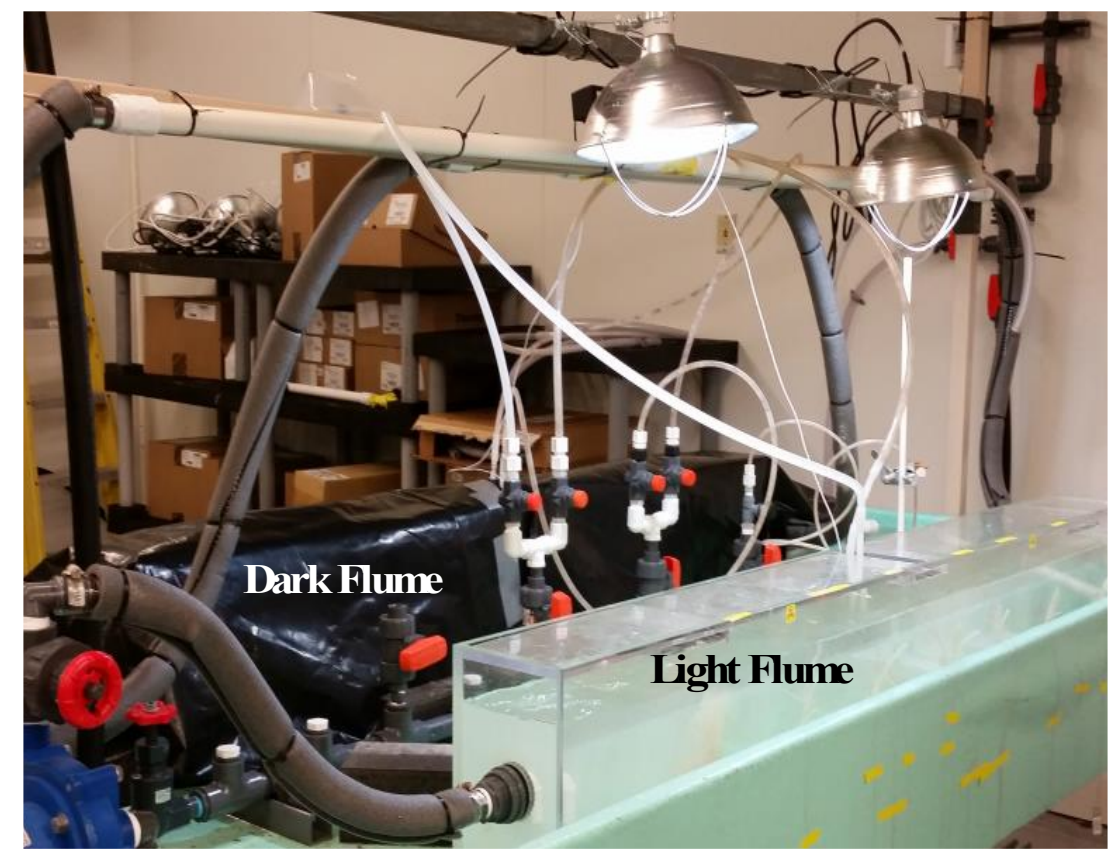

Figure 6. Light and Dark Flumes used for the Biofouling Exposure Study with 150 mm Filtered Seawater 
The overall sampling design and numbering scheme for this report and the companion milestone report are depicted in Figures 7 and 8. The determination of adsorption capacity is based on the mass of dry adsorbent ( $\mathrm{g}$ of element adsorbed per kg of dry adsorbent). For a study in which braided adsorbent material will be gaining mass as biofouling occurs, this poses difficulties in determining the adsorbent mass sampled from a master braid. For this initial experiment with braided material exposed in unfiltered seawater a series of side experiments were conducted to develop a procedure for determination of sample mass and to assess specific aspects of biofouling parameters. The description of these experiments follows.

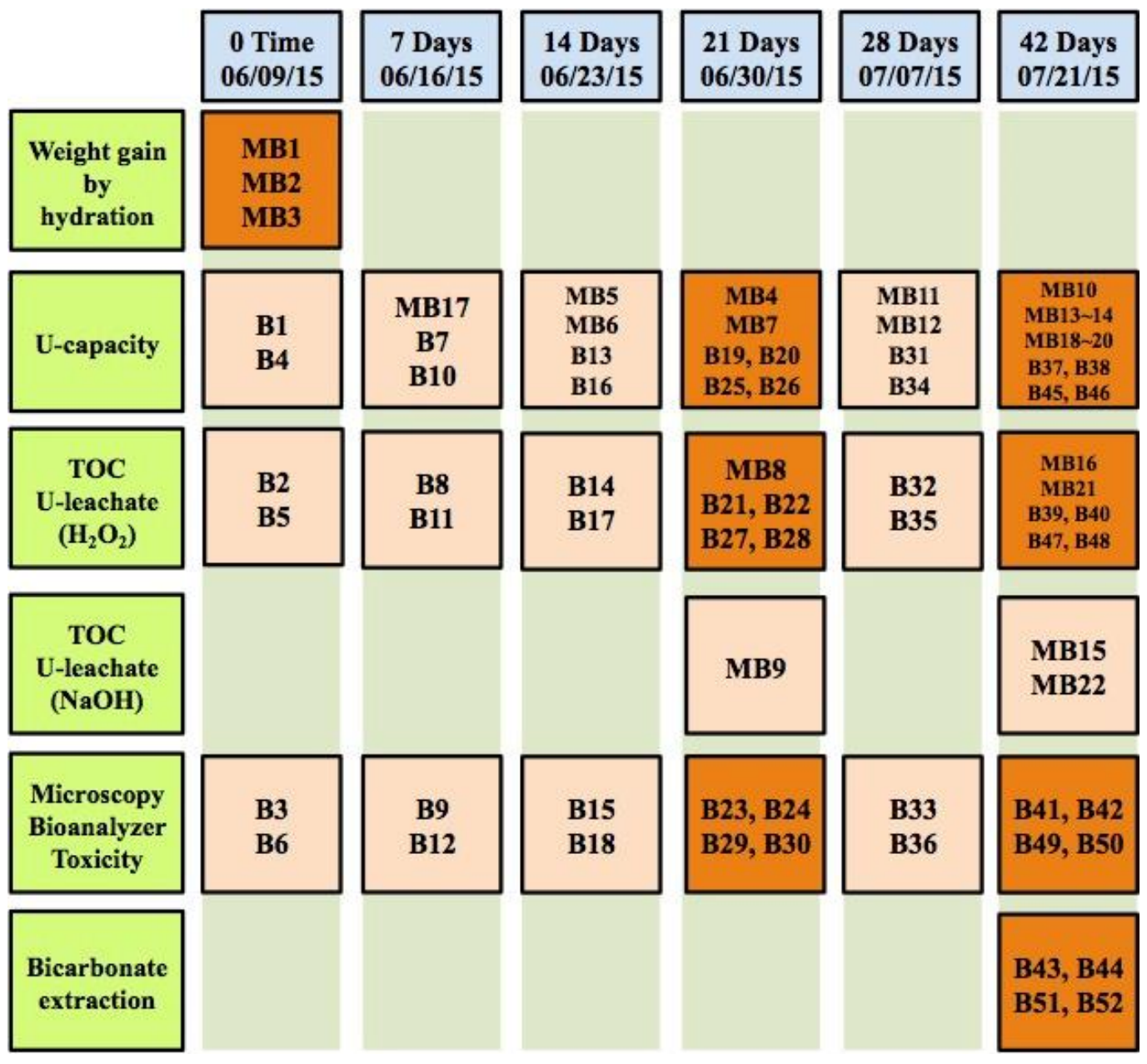

Figure 7. Overall Sampling Design for Determination of the Impact of Biofouling on Adsorption Capacity. The sampling periods are 0, 7, 14,21, 28 and 42 days. The individual experiments are given by the yellow boxes in each row. The darkened boxes represent where replicate samples were collected. $M B=$ mini braid, and $B=$ main braid. The \# indicates the specific sample number. 

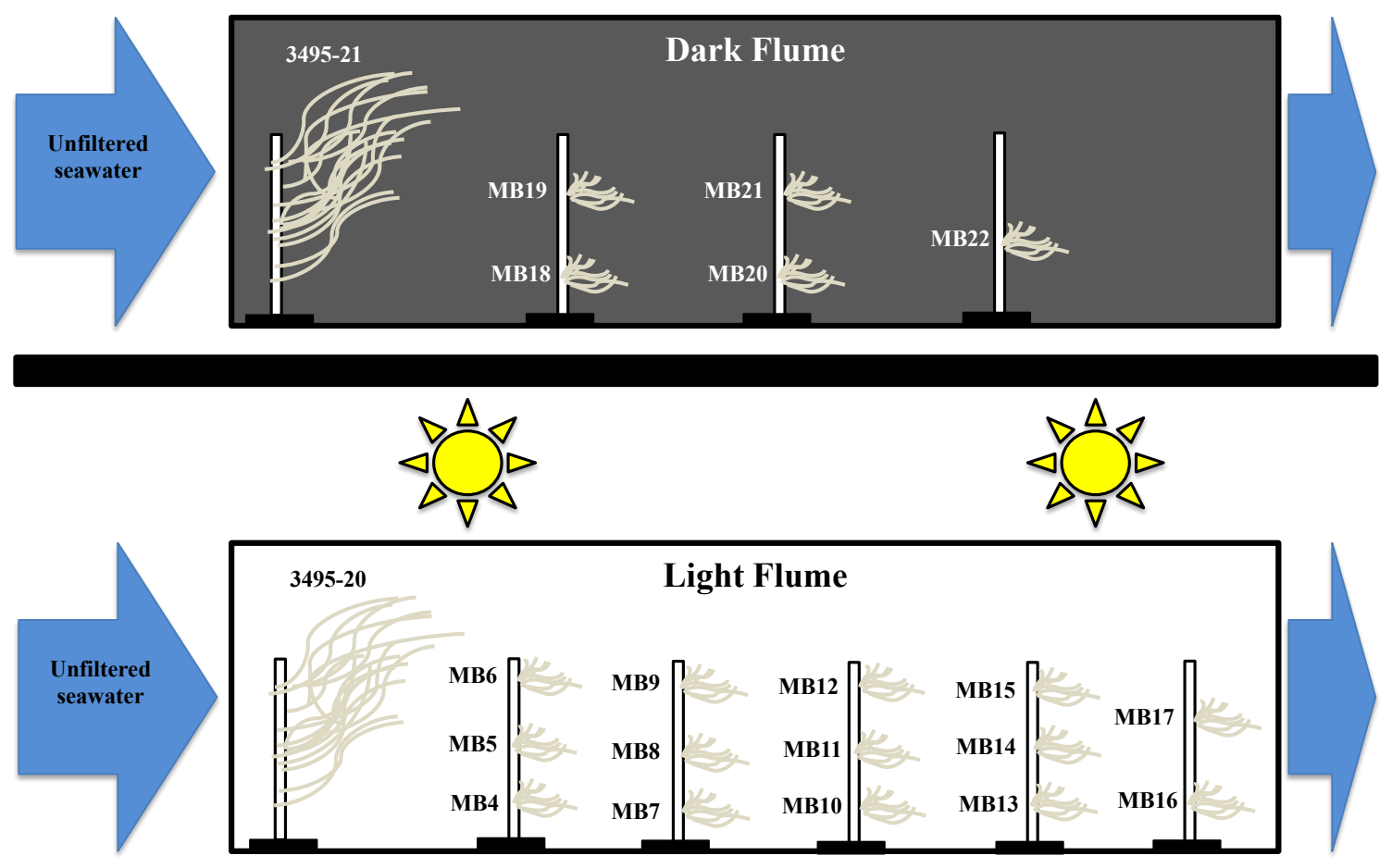

Figure 8. Layout of Main Braid and Mini Braids in the Dark and Light Flumes for the Unfiltered Seawater Biofouling Exposure Study. The main braid was positioned near the seawater recirculation inlet. The dark flume had 5 mini braids and the light flume had 14 mini braids

\subsubsection{Mass Accumulation of Biofouling with Time of Exposure}

To address the issue of adsorbent weight gain due to biofouling, a series of "snips" were collected off the main braid and were held together with fishing line. These "mini braids" are depicted in Figure 9. The mini braids were pre-weighed and deployed in both the light and dark flumes primarily to assess the mass gain of the adsorbent due to biofouling. A series of these mini braids were used to determine adsorption capacity with time. Snips off the main braid were also collected for uranium adsorption capacity determinations, as is the procedure with filtered seawater where no biofouling occurs.
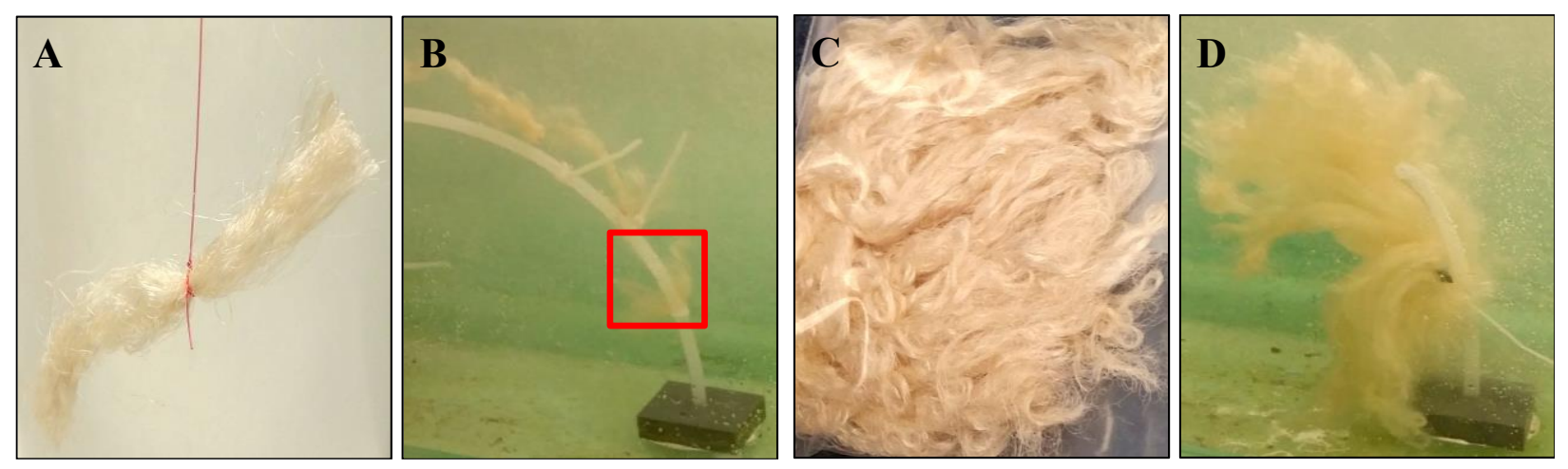

Figure 9. (A) Mini Braid Held Together with Fishing Line Prior to Conditioning; (B) Conditioned Mini Braids attached to tubing in the Flume $(C)$ Braided Adsorbent Before Conditioning with $\mathrm{KOH}$; (D) $\mathrm{KOH}$ Conditioned Braid Secured Inside the Flume. 


\subsubsection{Hydration Gain of Dry Adsorbent}

Three mini braids were immersed in the flume for approximately 5 minutes to assess the mass of water that the adsorbent will retain if removed from seawater and is not taken to dryness, but rather water is removed by centrifugation. This parameter is needed in conjunction with other tests to determine a final dry mass weigh.

\subsubsection{Uranium Capacity}

Time series adsorption capacity measurements of the ORNL AI8 amidoxime-based adsorbent were made in a similar fashion to previous determinations using filtered seawater in a darkened flume. Briefly, snips of approximately $100 \mathrm{mg}$ of adsorbent material were obtained at time points $0,7,14,21,28$ and 42 days by cutting off adsorbent "snips" from the master braid using a pair of titanium coated scissors. The snips were dried, weighed and digested in aqua regia for elemental determination. To correct for the mass of biofouling retained along with the adsorbent, the biofouling gain from the mini braids was used to predict the mass of biofouling per mass of adsorbent as a function of time. In addition, a series of mini braids were used to determine adsorption capacity as a function of time.

\subsubsection{Biofouling Mass Accumulation via Total Organic Carbon Measurements}

The amount of Total Organic Carbon (TOC) that was retained on the exposed braided material was determined as a means to estimate the mass of biofouling that accumulated on the adsorbent. Two approaches were used to strip organic matter off the braided material for determination by high temperature catalytic combustion analysis: (1) $1 \mathrm{M} \mathrm{NaOH}$ and (2) $0.88 \mathrm{M} \mathrm{(3.2 \%} \mathrm{v/v)} \mathrm{H}_{2} \mathrm{O}_{2}$. The amount of uranium that was co-removed by these leaching procedures was also determined. If these procedures did not remove uranium, they would provide a means to strip of organic matter prior to the determination of uranium and thereby get a dry weight due only to the adsorbent.

\subsubsection{Biofouling Study Parameters}

Snips off the master braid were retained for determination of a series of parameters to describe the biofouling of the adsorbent. Details associated with these measurements are given in the companion Milestone Report (M3FT-15PN0310057) entitled "Impact of Marine Biofouling on the Adsorption Capacity and Kinetics of Amidoxime-Based Uranium Adsorbent Materials".

\subsection{Results and Discussion}

\subsection{Biofouling of Adsorbent Material in Light and Dark Flume Exposures with $150 \mu \mathrm{m}$ Filtered Seawater}

The increase of mass that the mini braids experienced as a function of time in both light and dark flume exposures is shown in Figure 10. Shown in Figure 11 are pictures of the dark and light flumes at the beginning of the experiment and after 42 days of exposure to $150 \mu \mathrm{m}$ filtered seawater. These pictures visually illustrate that controlling light exposure can substantially reduce biofouling from photosynthetic organisms. 
There was a significant difference in biofouling between the light and dark flumes. The adsorbent material in the light flumes increased in mass by approximately $80 \%$ after 42 days of exposure to $150 \mu \mathrm{m}$ filtered seawater at $20{ }^{\circ} \mathrm{C}$. In contrast, the dark flume showed only a $20 \%$ increase in biomass for the same exposure time and temperature. Not surprisingly, the biomass accumulation rate in the light flume appears to be non-linear, with a rapid increase between 2 and 3 weeks, and then a slow or no increase after that. Variability in biomass accumulation at the 42 day exposure time in the light flume was high compared to that in the dark flume. No time course samples were collected in the dark flume with which to evaluate the time course of biomass increase.

We attempted to use the information in Figure 10 with which to correct the total mass observed in the snips from the main braid to determine the mass associated with only the adsorbent material without success. The adsorption capacity information that resulted from this correction approach made no sense. Hence, all adsorption capacity information presented in this report were obtained from the mini braid deployments only.

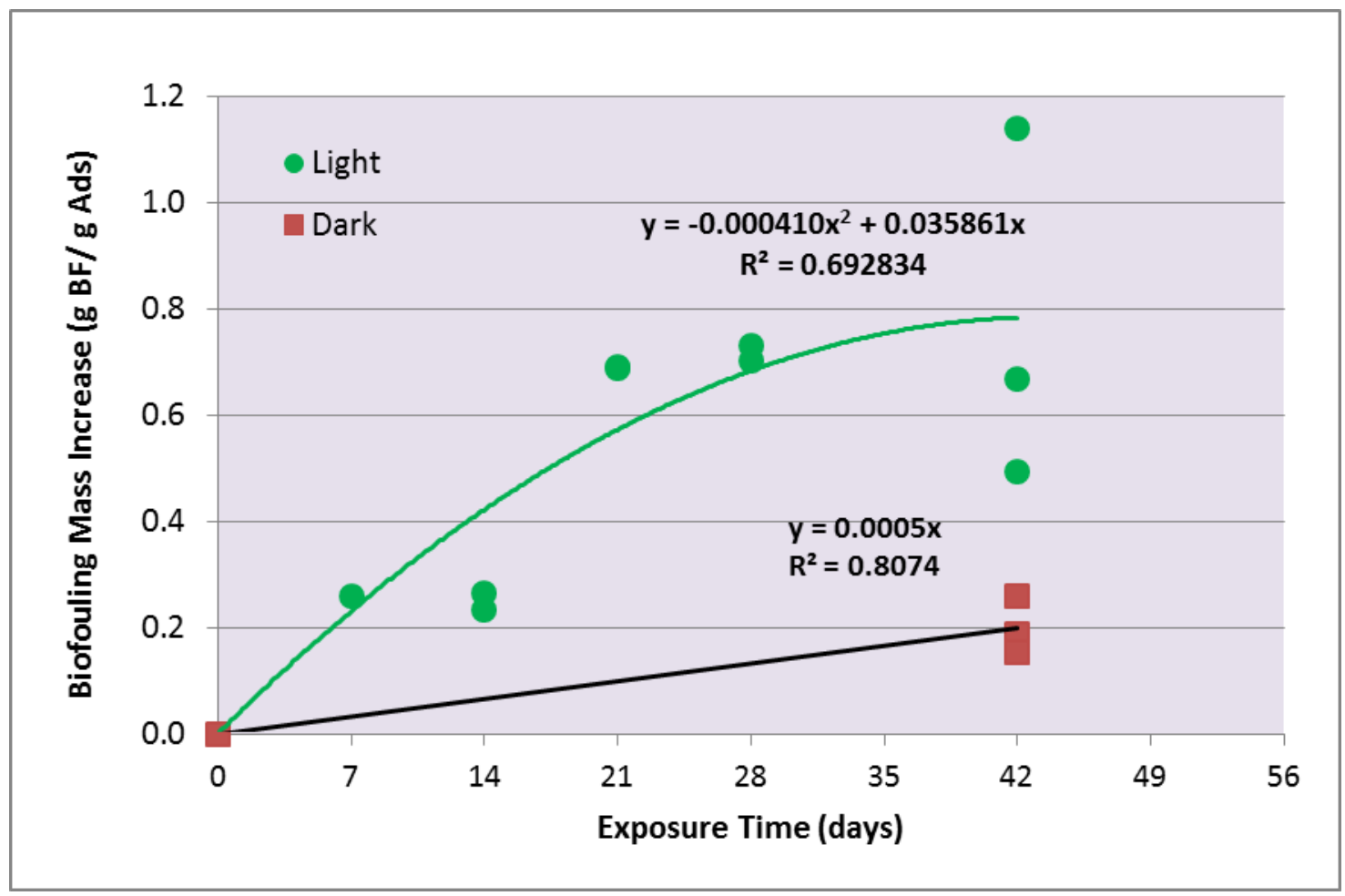

Figure 10. Biofouling mass accumulation as a function of time in light exposed and dark flumes for a 42 day exposue experiment with $150 \mu \mathrm{m}$ filtered seawater. 

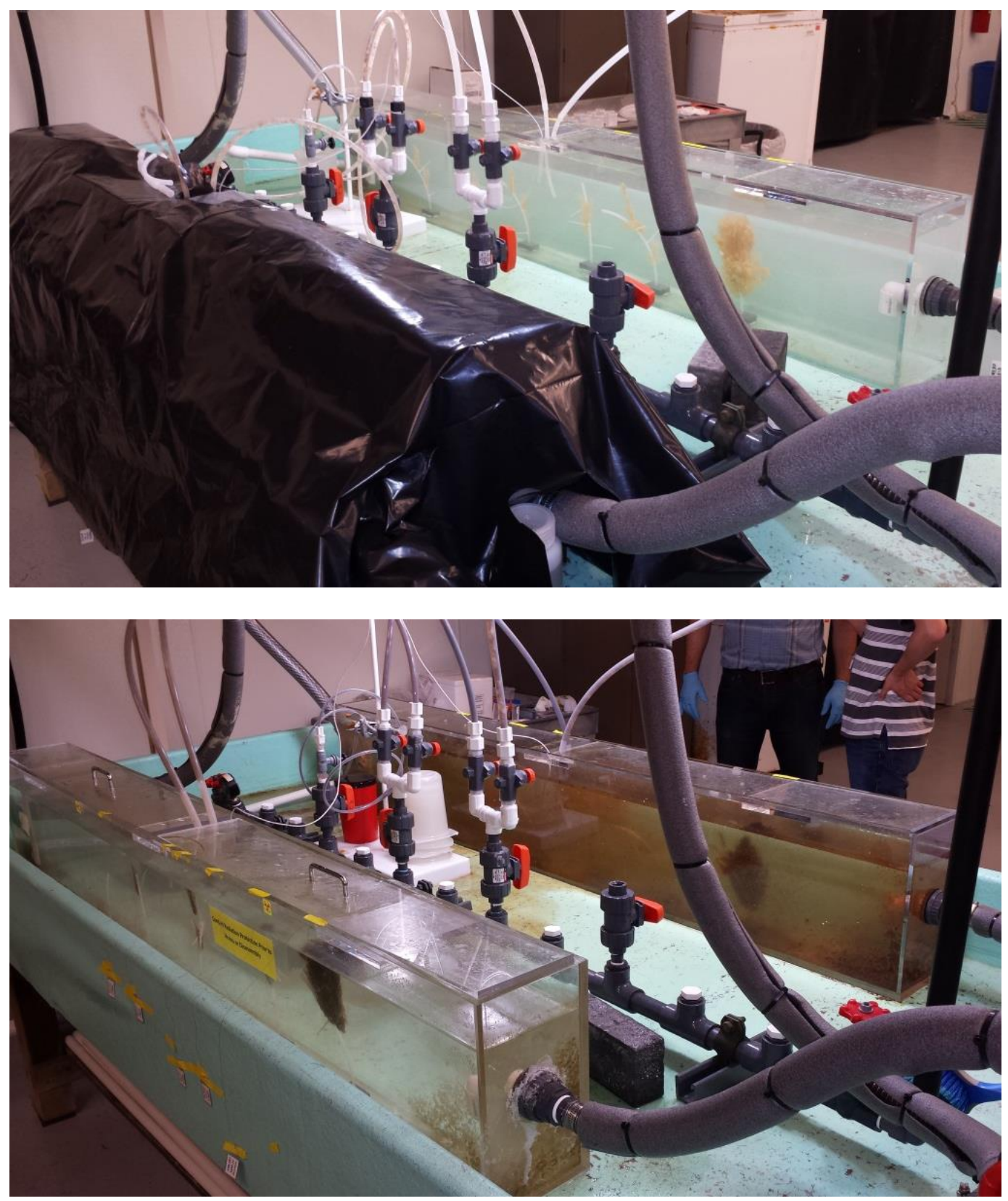

Figure 11. Light Exposed and Dark Bioflouling Experiment Flumes at the Start of the Experiment (Top Panel) and After 42 Days of Exposure to $150 \mu m$ Filtered Seawater (Bottom Panel). The Level of Biofouling in the Light Exposed Tank is Visually Apparent. 


\title{
4.2 Comparison of Uranium Adsorption Capacity in Dark and Light Flumes with $150 \mu \mathrm{m}$ Filtered Seawater Exposure
}

\begin{abstract}
Illustrated in Figure 12 are the time series results obtained for a 42 day exposure of the ORNL adsorbent AI8 in $150 \mu \mathrm{m}$ filtered seawater under both light exposed (green circles) and no light conditions (black squares) in the PNNL flume at $20{ }^{\circ} \mathrm{C}$. A quantitative comparison of the 42 day biofouling exposure experiment is given in Figure 13 and Table 2. The results presented are only for the mini braid samples. As noted previously, we were unable to use the information shown in Figure 10 to correct the snips collected from the main braid for biofouling mass increase such that we could determine the uranium uptake capacity for main braid samples. No time series samples were collected for the mini braid samples in the dark flume, only three replicates of the 42 day exposure. Also shown on Figure 12 (red diamonds) are the results of two sub-samples taken from the main braid and exposed for 42 days at the same time as the flume experiment using the PNNL flow-through column testing system with $0.35 \mu \mathrm{m}$ filtered seawater in no light conditions and at $20{ }^{\circ} \mathrm{C}$. These flow-through column exposure samples serve as a control sample as they are identical to the flume experiment, except they will not experience and any bioflouling due to dark exposure with filtered seawater. Finally, also shown on Figure 12 (blue points and line), as a reference, is a previous time series determination using the ORNL AI8 adsorbent with the PNNL flow-through column testing procedure using $0.45 \mu \mathrm{m}$ filtered seawater at $20^{\circ} \mathrm{C}$. Lines drawn through the data points are from one-site ligand saturation modelling.

The data from this experiment suggest that biofouling in sunlit surface seawater has the potential to reduce uranium adsorption capacity by $\sim 30 \%$ after 42 days of exposure. Minimal or no adsorption loss due to biofouling occurred in the dark flume exposure as evidenced by a similar response between the adsorption capacity in the flume and the AI8 adsorption material that underwent 42 day testing in a flowthrough column.
\end{abstract}




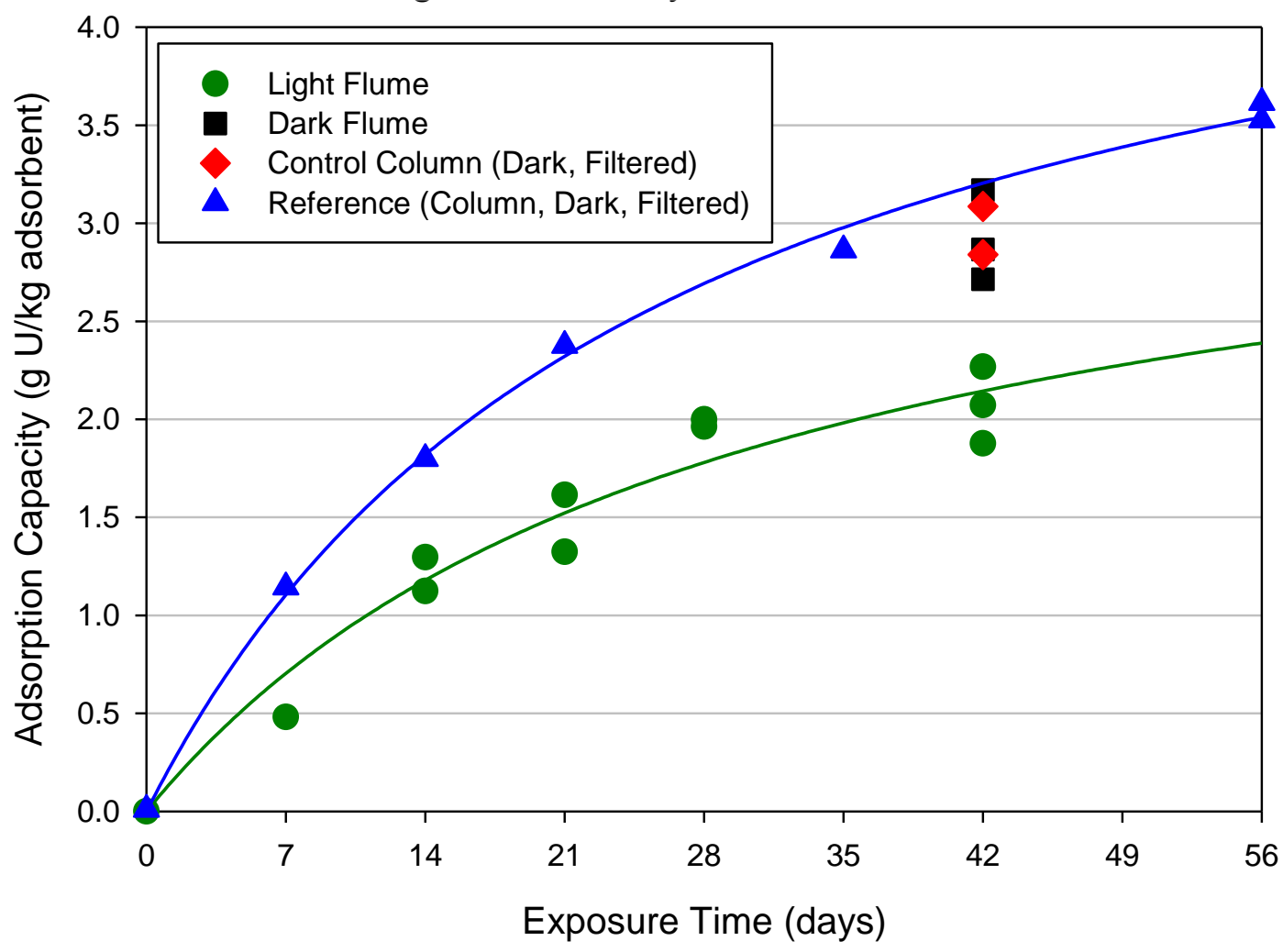

Figure 12. 42 Day Biofouling Experiment in the PNNL Flume with the ORNL AI8 Adsorbent. The green circles represent the time series results obtained from the mini braid samples in the light exposed flume. The black squares represent replicate measurements of the 42 day exposure time in the dark flume. The red diamonds represent a subsample of the main braid that was exposed in a PNNL flow-through column for 42 days in 0.35 um filtered water in the dark. This samples serves as a control. The blue triangles are from a previous time series experiment conducted with the ORNL AI8 adsorbent in flow-through columns exposures in the dark at $20^{\circ} \mathrm{C}$. This data serves as a reference only. Lines drawn through the data points are from one-site ligand saturation modelling. 


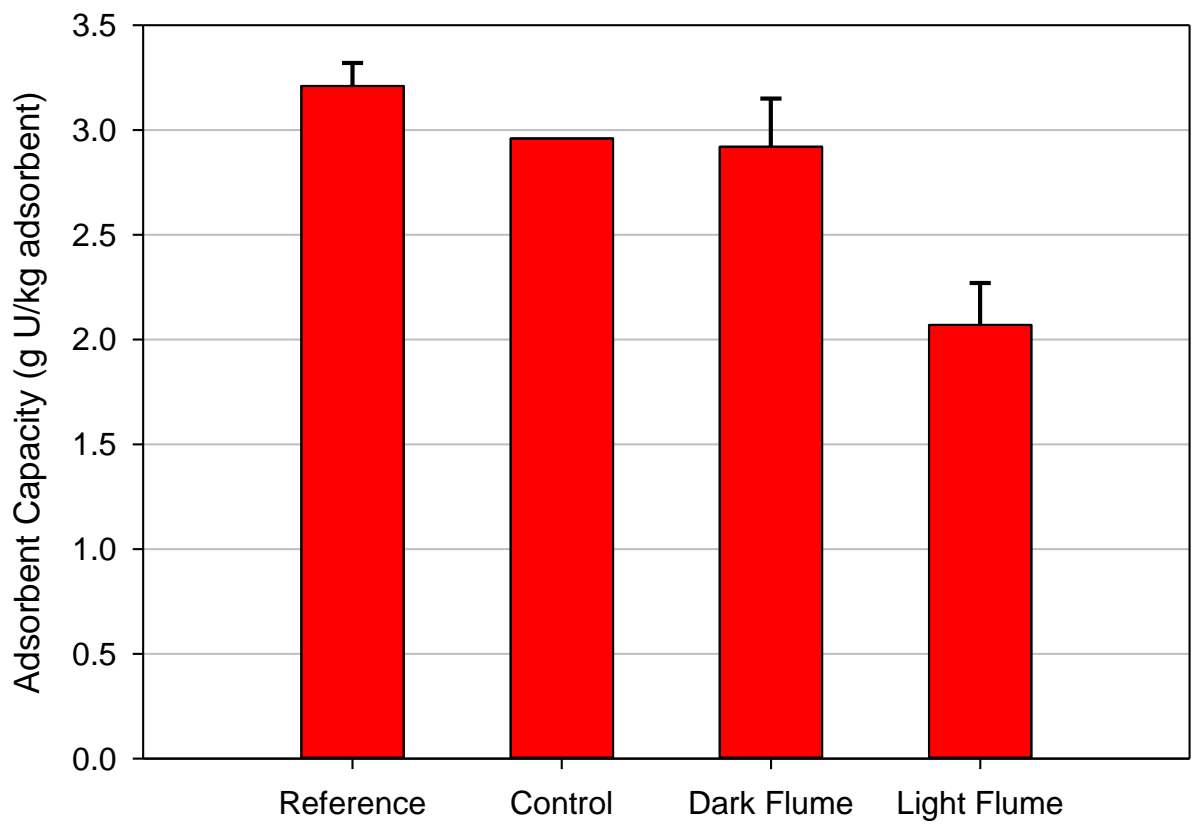

Figure 13. Comparison of 42 Day Exposure of the ORNL AI8 Adsorbent Capacity in Light Exposed and Darkened Flumes That Received 150 um Filtered Seawater. The Control Sample Represents Snips of the AI8 Braid Exposed to $0.35 \mu \mathrm{m}$ Filtered Seawater in a PNNL Flow-through Column Exposure. The Reference Sample Represents a Previous Time Series Experiment Conducted with the ORNL AI8 Adsorbent in Flow-through Columns Exposures in the Dark at $20^{\circ} \mathrm{C}$.

Table 3. Reduction in ORNL AI8 Adsorption Capacity Due to Biofouling after 42 days of Exposure in 150 $\mu \mathrm{m}$ Filtered Seawater. Reductions Were Determined Relative to a Reference Data Set (Independent of This Study) That Was Conducted in PNNL Flow-Through Columns With 0.35 um Filtered Seawater and With a Dark Exposure.

\begin{tabular}{|c|c|c|c|}
\hline & $\begin{array}{c}\text { Adsorbent } \\
\text { Capacity } \\
\text { (g U/kg adsorbent) }\end{array}$ & $\begin{array}{c}\text { Relative to } \\
\text { Reference }\end{array}$ & $\begin{array}{c}\text { Relative to } \\
\text { Control }\end{array}$ \\
\hline Reference & $3.21 \pm 0.11$ & & \\
\hline Control & $3.09,2.84$ & $7.8 \%$ & \\
\hline Dark Flume & $2.92 \pm 0.23$ & $9.0 \%$ & $1.4 \%$ \\
\hline Light Flume & $2.07 \pm 0.20$ & $36 \%$ & $30 \%$ \\
\hline
\end{tabular}

${ }^{1}$ Normalized to a salinity of $35 \mathrm{psu}$ 


\subsection{Conclusion}

PNNL has developed a flume system for exposing braided adsorbent material to natural seawater under realistic temperature and flow-rate exposure conditions. Because the flumes are constructed of transparent acrylic material they allow external light to pass into the flumes and permit photosynthetic growth of naturally present marine organisms (biofouling). Because the system consists of two flumes, replicate experiments can be conducted in which one of the flumes can be manipulated relative to the other. For example, one flume can be darkened to eliminate light exposure by placing a black tarp over the flume such that dark/light experiments can be conducted. Alternatively, two different braided adsorbents can be exposed simultaneously with no potential cross contamination issues.

Attempts to assess time series measurements of uranium adsorption capacity using "snips" off a master braid, as in previous filtered flume studies, are fraught with problems due to the inability to easily determine the mass of the adsorbent material when the biofouling is present. At this point, the only clear way to address this issue is to expose pre-weighed "mini-braids" that are created from the master braid. In this fashion, the original mass prior to deployment can be used and no correction procedure to account for biomass increase is necessary. The ability to determine the mass of adsorbent independent from biofouling is critical because all adsorption capacity measurements are mass based (e.g. $\mathrm{g} \mathrm{U} / \mathrm{kg}$ adsorbent).

The ability to determine the adsorption of biogenically important trace elements (e.g. Fe, $\mathrm{Mn}, \mathrm{Zn}, \mathrm{Cu}$, and $\mathrm{Sr}$ ) on biofouled adsorbents is also problematic. This difficulty arises because many of the elements of interest are also major components in biogenic material. When a biofouled adsorbed is digested for analysis, the concentrations that are observed are a result of the element retained on the adsorbent and the contribution from the biogenic material as well. For elements like uranium, this is not an issue because uranium is not a required element for biological growth and thus it is in extremely low concentrations in biogenic material. Additional study needs to be undertaken to determine which elements can be assed directly in the presence of biofouling. An alternate approach to overcome this issue is to develop a cleaning protocol to remove the biofouling from the adsorbent prior to any analytical efforts. Additional work on this approach is also warranted.

Biofouling in sunlight surface seawater has the potential to significantly add substantial biogenic mass to adsorption material when it is exposed for periods greater than 21 days. The observed biomass increase in the light flume was approximately $80 \%$ of the adsorbent mass after 42 days. The amount of biomass increase retained by the adsorbent in the dark flume was only a quarter of that observed in the light exposed flume.

Biofouling in sunlit surface seawater has the potential to reduce uranium adsorption capacity by $30 \%$ after 42 days of exposure. Minimal or no adsorption loss due to biofouling occurred in the dark flume exposure. While these observations are preliminary, they offer a fairly simple approach for minimizing biofouling impacts when this technology is used in a real world deployment - deploy the adsorbent where photosynthesis is minimal. There are two obvious ways to accomplish this in marine systems. First, deploy the adsorbent material below the photic zone and second, deploy the adsorbent material in low primary production oceanic regions, often described as "clear or blue water" regions. Light penetration into the oceans can vary significantly with region, but low light levels are frequently obtained at depths greater than 50-100 m. The downside to deployment at greater depths is that temperature drops off with depth and warmer temperatures are favorable to adsorption capacity. A measure of primary productivity in the ocean is chlorophyll a concentration (Figure 14). Most coastal 
regions tend to be more productive and open ocean areas low productivity. There are many exceptions. For example, the south east coast of the US (e.g. Florida) tends to be low productivity area.

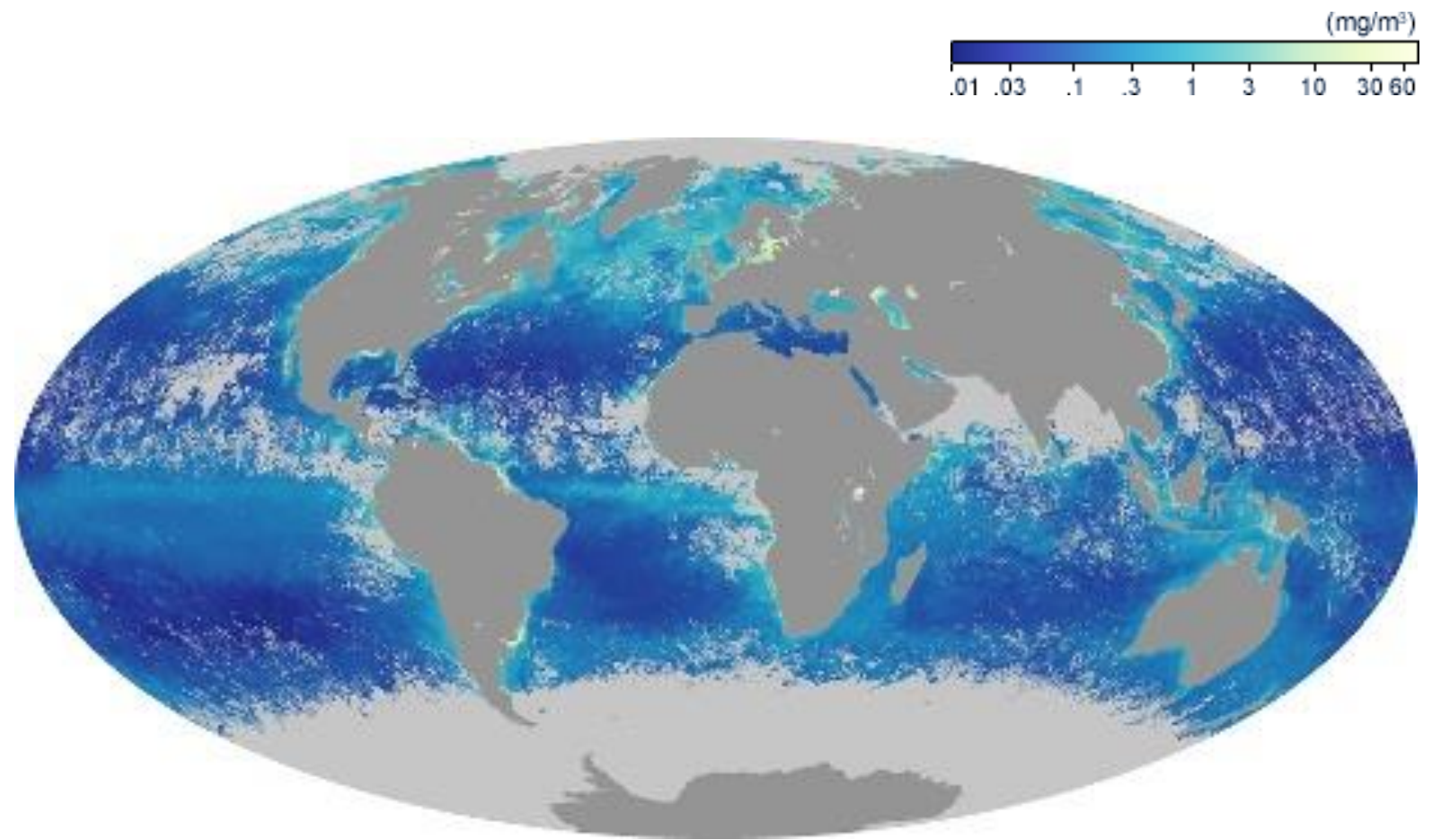

Figure 14. Global Chlorophyll a concentration (figure from NASA; http://earthobservatory.nasa.gov/GlobalMaps/view.php?d1=MY1DMM_CHLORA)

\subsection{References}

DOE. 2010. Nuclear Energy Research and Development Roadmap: Report to Congress. U.S.

Department of Energy, Washington, D.C. Available at: http://energy.gov/ne/downloads/nuclear-energyresearch-and-development-roadmap. 